\title{
Conductor Joint Performance During The Ebasco Team SMES POPE (Proof of Principle Experiment)
}

\author{
D. W. Scherbarth, O. R. Christianson, E. F. Daly, T. Kupiszewski, and D. Marschik \\ Westinghouse Science \& Technology Center, Pittsburgh, PA
}

\author{
J. M. Pfotenhauer, M. K. Abdelsalam, O. D. Lokken, and J. S. Waldrop
}

University of Wisconsin-Madison, Madison, WI

\begin{abstract}
A joint in the superconductor and stabilizer is added to the ETM conductor in the POPE. The joint design is similar to that proposed by Westinghouse for the SMES ETM field joints. Fabrication of the joint is described. Measurements on the performance of the superconducting joint operated in subcooled $H e ~ I$ and of the stabilizer joint at $14 \mathrm{~K}$ are reported. Measured superconductor joint resistance is $1.6 \mathrm{n} \Omega$, which agrees with previous analytic calculations. The stabilizer joint $\mathbf{R R}$ matches the conductor stabilizer $\mathbf{R R}$. The joint met or exceeded all operational requirements throughout the experiment demonstrating its reliability and small joule heating.
\end{abstract}

\section{INTRODUCTION}

The test coil for the POPE (Proof of Principle Experiment) is three one meter diameter turns of conductor consisting of eight $\mathrm{Cu} / \mathrm{Nb} / \mathrm{Ti}$ superconducting strands soldered into grooves in the $2.54 \mathrm{~cm}$ diameter high purity aluminum (HPAL) stabilizer, shown in Fig. 1. This cross section is identical to that of the conductor proposed for a larger SMES coil [1]. The total conductor length in the POPE test coil, including the leads, is 11 meters. A schematic layout of the test coil is shown in Fig. 2. The POPE apparatus also includes a split pair solenoid to provide a background field for the test coil. The test coil is sandwiched between the two halves of the background coil. The coil assembly has undergone various tests at the University of Wisconsin over a period of 1989-1993 [2], [3].

In its original configuration, the conductor for the POPE test coil did not have any strand joints. The stabilizer contained one joint, approximately in the middle of its length. This joint was made by flash butt welding of the aluminum prior to inserting the strands into the groove during the initial construction of the test coil in 1989, and has operated well ever since.

A full size SMES will contain many stabilizer and strand joints. These joints will be made at the construction site as the coil is being wound, and are thus called "field joints." The proposed field joint consists of a flash butt welded joint in the aluminum stabilizer, and cold upset welds in each of the eight superconducting strands. For each weld the upset material is trimmed away, so that the cross section of the conductor is maintained through the joint area. In general, joints would not be noticeable, except under close visual inspection. Since the conductor is immersed in a helium bath, there are no cryostat or conduit joints that must coincide with the conductor joint.

A failure in the positive lead of the POPE test coil occurred in August 1993. The failure occurred due to current being applied during a $\mathrm{RR}$ test at $15 \mathrm{~K}$ for an excessive period of time. The aluminum conductor and superconducting strands melted in a section of the positive lead at the location shown in Fig. 2. This failure required a rapid fix in order to finish the POPE testing on schedule and presented the opportunity of testing a repair similar to the proposed field joint in a large SMES.

The POPE test coil is repaired in one month, allowing completion of the test program on schedule. Despite tight schedule and significant technical constraints caused by the nature of the in-situ repair, a satisfactory joint is produced. In this report, we describe the fabrication and performance of this joint. Through this effort, we have gained valuable

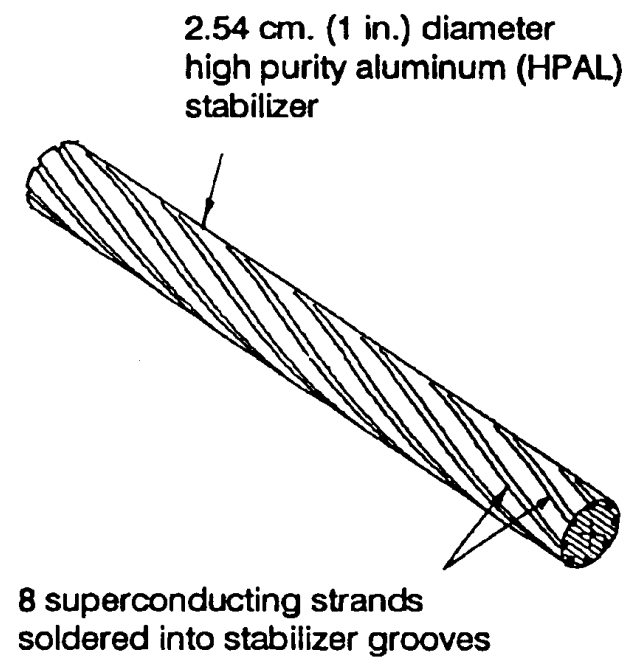

Fig. 1. SMES conductor design used in the POPE test coil.
Manuscript received October 17, 1994. This work was supported by the Defense Nuclear Agency, under contract DNA001-92-C-0064. 
experience and data relevant to the SMES field joint. The results show that the SMES field joint is feasible, from the standpoint of both implementation and performance.

\section{DESCRIPTION OF REPair}

\section{A. Options Considered}

A rapid repair effort is carried out by the SMES Ebasco team at Westinghouse STC. Two options are identified. Option 1 consists of replacing the damaged lead with a massive cryostable copper bus. Option 2 calls for the replacement of the damaged lead with a new section of SMES conductor. This new length of conductor is welded to the existing POPE conductor by TIG welding the stabilizer, and cold upset welding the strands. A flash weld for the stabilizer is ruled out because of spatial and schedule

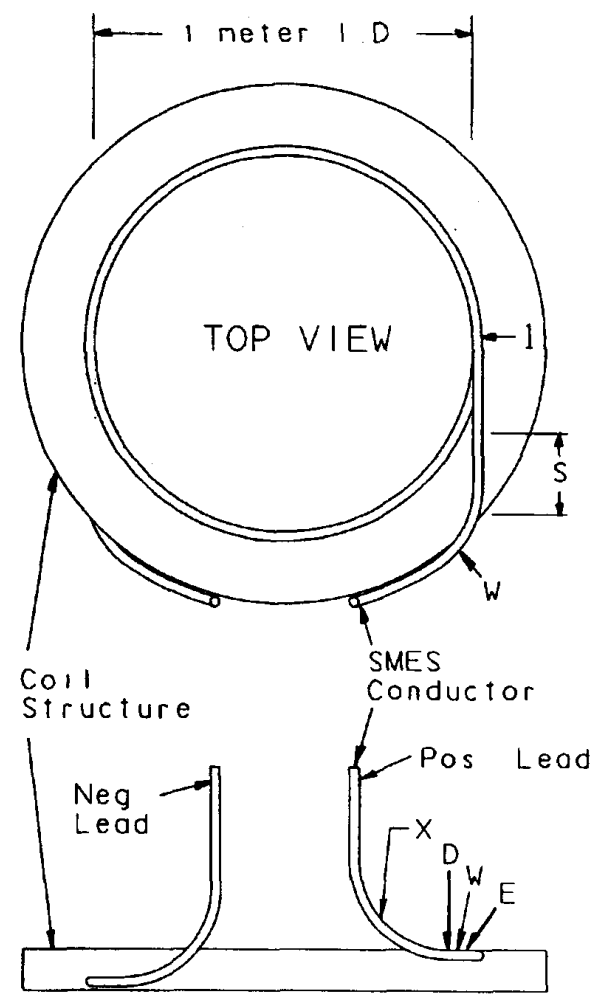

$$
\text { SIDE VIEW }
$$

Fig. 2. The POPE test coil consists of SMES conductor wound into three one meter diameter turns. $\mathrm{X}$ is the location of the conductor failure. $W$ is the location of the stabilizer TIG weld. $S$ is the range of the strand welds. Voltage taps are at $\mathrm{D}, \mathrm{E}$, and $\mathrm{I}$. constraints. Much of the test coil would have had to be disassembled to make it accessible to the relatively large flash welding equipment, and this would have taken too long. In Option 2, the repaired coil would appear identical to the original one.

Option 2 is chosen for the repair and had several advantages over Option 1. Option 2 is not a design change, but rather, the conductor is simply being restored to its original configuration. Option 2 also is more relevant to the overall SMES concept, because the repair is similar to a field joint.

\section{B. Stabilizer Weld Development}

A brief weld development program is carried out at Westinghouse under the guidance and consulting support of the Ebasco SMES team. The key element of risk in the Option 2 repair is whether or not a pure, low resistance, mechanically sound TIG weld could be made in the HPAL stabilizer. Over an 11 day period, 4 sample welds are made, and 3 attempts are made at welding the new lead stabilizer to the POPE test coil stabilizer. The third attempt is successful.

There are several characteristics common to all welds. A Lincoln TIG welder, model TIG-250/250 is used. The base metal is SMES HPAL stabilizer rod, $2.54 \mathrm{~cm}$ in diameter. The filler metal consists of $0.15-0.30 \mathrm{~cm}$ diameter rods of HPAL, that are made by swaging down the larger stabilizer rod. The shield gas is Argon, and the only source of the Argon is the welder itself. There is no glove box, or secondary source of shield gas. Weld quality is assessed by measuring the RRR of the weld using the eddy current decay method [4].

TABLE 1

Summary of Sample and Repair Welds

\begin{tabular}{|c|c|c|c|}
\hline $\begin{array}{c}\text { Weld } \\
\text { Number }\end{array}$ & Description & $\begin{array}{c}\text { Preweld } \\
\text { Condition }\end{array}$ & $\begin{array}{l}\text { Postweld } \\
\text { Evaluation }\end{array}$ \\
\hline 1 & TIG Sample & $\mathbf{G}$ & $\begin{array}{c}\mathrm{RRR}=1800- \\
3100\end{array}$ \\
\hline 2 & TIG Sample & $\mathbf{G}$ & Bend Test OK \\
\hline 3 & TIG Sample & $\mathrm{G}, \mathrm{T}, \mathrm{S}$ & $\mathrm{RRR}=4700$ \\
\hline 4 & Repair \#1 & G,T,S & $\begin{array}{c}\text { Cracks- } \\
\text { Unacceptable }\end{array}$ \\
\hline 5 & TIG Sample & G,T,S & Bend Test OK \\
\hline 6 & Repair \#2 & $\mathrm{G}, \mathrm{T}, \mathrm{S}$ & $\begin{array}{c}\text { Cracks- } \\
\text { Unacceptable }\end{array}$ \\
\hline 7 & Final Repair & G,T,S & $\begin{array}{c}\text { Slight Cracking } \\
\text { OK for POPE } \\
\text { Tests }\end{array}$ \\
\hline 8 & Flash Sample & $\mathbf{G}$ & $\begin{array}{c}\mathrm{RRR}=2000- \\
2900\end{array}$ \\
\hline Key: & $\begin{array}{l}\text { zer rod is groo } \\
\text { zer rod is twist } \\
\text { originally pres } \\
\text { elding. }\end{array}$ & $\begin{array}{l}\text { ore weldi } \\
\text { re weldin } \\
\text { stabilizer }\end{array}$ & but removed \\
\hline
\end{tabular}


Various sample and repair welds are summarized in Table $\mathrm{I}$, and are described in more detail in the following text.

Weld \#1. Sample. A TIG weld is made in a piece of grooved, untwisted, untinned HPAL stabilizer. A point prep is put on each piece. This weld is done on a bench top with good accessibility. There is no heat applied before, during, or after the weld, except the heat provided by the torch itself. After the weld, the piece is uncovered and allowed to air cool. After welding, the straight grooves are milled out through the weld. The weld is then sectioned and RRR tested by an eddy current method. Westinghouse measures the RRR at 3100, and University of Wisconsin measures the RRR at 1800 . Even the lower value of 1800 significantly exceeds the team's goal of achieving a RRR of 600 in the stabilizer weld.

Weld \#2. Sample. Similar to weld \#1. After groove machining, the piece is annealed at 340-360 C for 3 hours. It is then bent 90 degrees over a sharp corner. The weld is centered at the bend. There are no visible cracks, and the weld appears ductile and nonporous.

Weld \#3. Sample. The sample stabilizer is grooved, twisted, and tinned prior to prepping for welding. After the point preps are machined, the solder is removed with a stainless steel brush. The pieces are held in a fixture, and inclined to simulate the orientation and access of the actual weld. The holding fixture contains water cooled chill blocks to prevent overheating of the stabilizer away from the weld. As in prior sample welds, there is no heat applied to the weld, other than that generated by the torch. This weld is sectioned and RRR tested as the first sample was. A RRR measurement of 4700 is obtained at Westinghouse STC.

Weld \#4. 1st Attempted Repair. After welding, the grooves are machined and tinned with solder, in preparation for soldering in the superconducting strands. Two days after welding, cracks are discovered in the stabilizer weld. The welded section is cut out and bend tested, as weld \#2 was. The bend test produces tearing along the cracks. However, the piece does not break, and it appears that approximately $50 \%$ of the weld cross section is ductile and crack free. The most likely reason for the weld defects is the lack of applied heat before, during, and after the weld.

Weld \#5. Sample. This sample is similar to weld \#3. The difference is that a vertical chisel point prep is used instead of a conical point. This proves slightly easier to weld, because there are fewer passes on the bottom of the stabilizer. Also, the technique of machining the grooves after welding is improved with better fixturing. By improving the fixturing, the machining process is made more efficient and controlled, thereby limiting the work hardening imparted on the HPAL stabilizer. After groove machining, the sample is annealed and bent. The sample passes the bend test with only small shallow cracks at the surface.

Weld \#6. 2nd attempted repair. Cracks are discovered a day later. After further probing and inspection, the weld broke clear through, revealing a void at the root. It appears that full penetration is not achieved.

Weld \#7. 3rd and final attempted repair. This is successful, and POPE testing is performed with this weld. The weld is heated to annealing temperature $(343 \mathrm{C})$ for one hour prior to welding. Heat is maintained during welding with torches. We estimate that the base metal temperature remained above $300 \mathrm{C}$ during the entire 1 hour duration of the weld. After welding, the weld is annealed at $340 \mathrm{C}$ for 3 hours, and cooled at a rate of $28 \mathrm{C} / \mathrm{hr}$ or less to a temperature of $240 \mathrm{C}$. At this point, the heater is turned off, and the covered weld is allowed to passively cool to room temperature.

Weld \#8. This was a flash butt weld sample made in 1989. It was sectioned and RRR tested with the same procedure used for the TIG samples. The RRR measurements obtained by Westinghouse and University of Wisconsin were 2900 and 2000 , respectively.

\section{Final Assembly of Joint and Lead}

After the stabilizer weld is made, the grooves are machined through the weld area. After machining, the weld area is annealed to remove the effects of work hardening produced by the groove machining. Then the grooves' surfaces are tinned with $63 / 37 \mathrm{Tin} / \mathrm{Lead}$ solder. The strand joints are made by cold upset welding. After trimming the upset material from the strand welds, the strands are retinned at the weld area, and inserted into the stabilizer grooves. Up until this point, the stabilizer is straight in the weld and lead region. The next step is to form the stabilizer and strands into the compound bend shown in Fig. 2. The inner radii of these bends are 0.24 meters. The relative positions of the stabilizer and stand welds are shown in Fig. 2. The eight strand welds are fairly evenly spaced over a 22 $\mathrm{cm}$ distance. The stabilizer weld is $10 \mathrm{~cm}$ from the nearest strand weld.

After forming the conductor, the solder bond between the strand and stabilizer is made by locally melting and reflowing the existing solder, while simultaneously adding new solder. In all soldering operations, bulk heating of the stabilizer is applied with a torch, and local heating of the solder joint was aided by an ultrasonic soldering pen.

\section{JoINT PERForMANCE}

\section{A. Instrumentation}

Voltage taps are placed on each side of the stabilizer joint, taps D and E in Fig. 2, and the strand joint, taps E and 1 in Fig. 2. The voltage taps are not non-inductively wound because they were used in multiple combinations for different experiments. 


\section{B. Stabilizer Joint}

The stabilizer joint resistance is measured during the $R R$ measurement for the conductor. The temperature of the conductor is $14 \mathrm{~K}$ in a helium gas environment. Temperature is maintained for an extended time period by limiting the transfer of LHe. Measurements give an RR of 1043 that compares well with the stabilizer AI RR outside the joint region, which is 1025 at $20 \mathrm{~K}$.

\section{Strand Joint}

The strand joint configuration is determined by using finite element analysis simulations of steady-state current diffusion between the strands and the surrounding stabilizer [5]. Strand joint resistance as a function of strand splice separations is calculated from the total heat generation. The strand joint separation is chosen as $3.175 \mathrm{~cm}$ based upon the strand resistance and superfluid cooling [6].

The strand joint resistance is measured in superfluid helium at $1.9 \mathrm{~K}$ in the self field of the test conductor. Magnetic field analyses indicate a large magnetic field gradient within the stabilizer, where the magnetic field ranges from $0.25 \mathrm{~T}$ at the center of the conductor to as large as $1.6 \mathrm{~T}$ at the surface of the strand at $60 \mathrm{kA}$. The strand joint voltage is measured during ramp of the test conductor up to 40,60 , and $75 \mathrm{kA}$. The resistance is determined by calculationaly eliminating the inductive contribution by calculating $\Delta \mathrm{V} / \Delta \mathrm{I}$, or by subtracting out the inductive contribution by performing a least square fit upon $V / I$ and finding the intercept, the resistance, and the slope, the inductive contribution.

$$
\frac{V}{I}=R-\frac{L}{I} \frac{d l}{d t}
$$

The values obtained are $1.6 \pm 0.3 \mathrm{n} \Omega$, which matches previous calculations, Fig. 3, for a similar configuration.

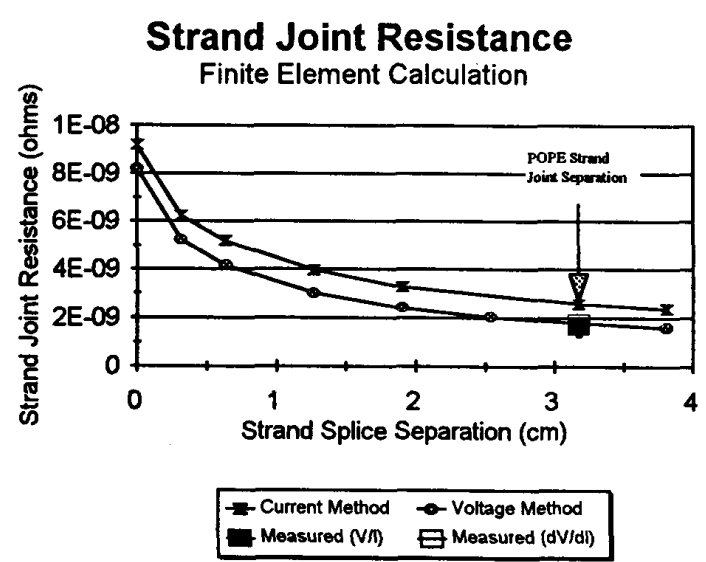

Fig. 3. Calculated strand joint resistance as a function of splice separation [6] and measured resistance values.

\section{Conclusions and Summary}

A joint consisting of a weld in the HPAL stabilizer, and a set of welds in the eight superconducting strands was added to the POPE test coil in September 1993. The joint enabled the Ebasco SMES team to complete POPE testing, as described in section III of this report, and in [3]

The strand joints show a low resistance of $1.6 \mathrm{n} \Omega$, which matches analytical predictions, and confirms that this joint will have a negligible impact on losses and stability in a large SMES coil. The strand joints can be easily made as part of a routine field joint during SMES construction or can be implemented in a confined environment that may exist in an unplanned in-situ repair.

The two stabilizer joints performed well. The flash weld included during the initial construction in 1989 has functioned well and has been problem free throughout the life of the coil. The second stabilizer joint, a TIG weld made during a repair to the positive lead section of the conductor, is a qualified success. Although it does have some cracks, the weld survives the test cycle without adversely affecting overall performance. The extent of the weld cracks does not get noticeably worse through the testing. The TIG welding offers a potentially attractive alternative to flash welding, because the equipment is smaller and more portable.

\section{ACKNOWLEDGMENTS}

We gratefully acknowledge Dr. K. Ted Hartwig for discussions concerning the stabilizer joint weld, Eric Brogren for guidance in making the stabilizer joint weld, and Dr. G. T. Mallick for performing the RRR measurements on the weld samples. The coil joint is fabricated by P. G. Moyer, R. R. Ronallo, and N. E. Mains.

\section{REFERENCES}

[1] O. R. Christianson, Y. M. Eyssa, X. Huang, S. K. Singh, and R. W. Boom, "Conductor selection for SMES applications," Advances in Cryogenic Engineering, Vol. 39, pp. 821-828, 1994.

[2] J. M. Pfotenhauer, M. K. Abdelsalam, B. Dodker, D. Huttleston, Z. Jiang, O. D. Lokken, D. Scherbarth, B. Tao, and D. Yu, "Test results from the SMES proof of principle experiment," IEEE Transactions on Magnetics, Vol. 27, No. 2, pp. 1704-1707, March 1991.

[3] J. M. Pfotenhauer, M. K. Abdelsalam, E. Brogren, O. R. Christianson, E. F. Daly, D. DeGraaf, F. Kessler, J. E. King, O. D. Lokken, A. Ludbrook, D. Pavlik, Z. Jiang, J. Waldrop, and S. Yang, "Performance Characteristics of the $60 \mathrm{kA}$ SMES conductor," paper LEC-2 this conference.

[4] C. P. Bean, R. W. DeBlois, and L. B. Nesbitt, "Eddy-current method for measuring the resistivity of metals," Journal of Applied Physics, Vol. 30 , No. 12, pp. 1976-1980, December, 1959.

[5] T. Kupiszewski and O. R. Christianson, "Strand joint losses in superconductors employing monolithic high purity aluminum stabilizers," Advances in Cryogenic Engineering, Vol. 40, pp. 677-683, 1994.

[6] T. Kupiszewski, "Calculation of strand splice separation in the SMESETM conductor," Westinghouse Electric Corp. STC Document No. 939TM3-SMRRB-RI, September 23, 1993. 